\title{
Optimizing Container Truck Dispatching of Container Terminal Through Cooperative Scheduling Strategy
}

\author{
Ching-Kuei Kao ${ }^{1,}$, , Si Zheng ${ }^{2}$ \\ ${ }^{1}$ Key Laboratory of LNG Industry Chain, Fujian University of Technology, Fuzhou City, China \\ ${ }^{2}$ Department of Logistics Management, Beijing Institute of Technology, Zhuhai, Zhuhai City, China
}

Email address:

ckkao@fjut.edu.cn (Ching-Kuei Kao), 942949683@qq.com (Si Zheng)

${ }^{*}$ Corresponding author

\section{To cite this article:}

Ching-Kuei Kao, Si Zheng. Optimizing Container Truck Dispatching of Container Terminal Through Cooperative Scheduling Strategy. International Journal of Transportation Engineering and Technology. Vol. 6, No. 3, 2020, pp. 61-74. doi: 10.11648/j.ijtet.20200603.11

Received: July 15, 2020; Accepted: July 29, 2020; Published: August 4, 2020

\begin{abstract}
Container terminals are the hubs that connect seas and lands in international transportation. In the globalization context of trade, the pursuit of efficient terminal operation is the goal of container terminals, transportation companies, and local governments. As a connecting transportation tool for terminal loading and unloading operations, horizontal transport, and storage operations, the operation of container trucks is optimized on the basis of a coordinated scheduling strategy with terminal working machinery in order to be in line with the concept of high-efficiency operation. Thus, the shortest operating time of ships is taken as the goal, and then the variables of the docking position of the ship and the number of quay crane operations are considered, a model for the three major processes of ship docking is developed, including the docking of ships and the number of quayside operations by arranging storage, transportation, and quay cranes and container trucks in the backyard. Subsequently, an evolutionary algorithm in Excel solver is used for the calculation of the examples, and the effectiveness of stack scheduling in optimizing terminal operation is finally confirmed on the basis of the cooperative scheduling strategy. According to the analysis results, $23.43 \%$ of the operation time can be saved under the loading and unloading coordinated container operation.
\end{abstract}

Keywords: Container Terminal, Container Truck, Cooperative Scheduling Strategy, Evolutionary Algorithm

\section{Introduction}

Given the rapid development of global trade integration and e-commerce network informationization, international trade has become more frequent, which has brought tremendous development opportunities to global container transportation. According to the statistics of China's port network on national port throughput, the throughput of China ports has shown a steady growth trend in the past seven years. In 2013-2016, the cargo throughput of China ports was approximately 10 billion tons. By 2017, the cargo throughput of China ports reached 12.6 billion tons, with a year-on-year growth rate of $6.4 \%$, and container transportation accounted for a large proportion of port transportation. In recent years, container throughput of China ports has shown a growth trend with the increase of port throughput. In 2012-2014, container throughput achieved a rapid growth rate, with year-on-year growth rates of $8.31 \%$, $7.42 \%$, and $6.20 \%$, respectively. In 2017 , the container throughput of China ports exceeded $18 \%$ in growth, symbolizing the recovery of the shipping market [1], also placing the shipping logistics service in the list as the key construction in the deep cooperation project between Guangdong and Hong Kong [2].

Shipping logistics services refer to the imported and exported business services provided by port enterprises and third-party logistics companies. The main business process links include canvassing, taking orders, tallying, booking, handling cargo insurance, cargo inspection and customs declaration, cargo loading and unloading, issuing bills of lading, and paying orders [3]. The upgrade of shipping logistics services can be started from two aspects. The first aspect is strengthening the investment on and construction of the hardware strength of port terminals, including the expansion of large facilities, such as docks, yards, and berths, and the acquisition and commissioning of advanced automated or semi-automated quay and gantry cranes. However, transforming the hardware of container port 
terminals often requires high investment costs and long construction periods. Container port terminals are difficult to upgrade from the hardware side because of high collection and distribution requirements and complex port operations, and a long period is required to see the effect. The second aspect is investing and improving the software strength of the existing resources of port terminals. Through the systematic and intelligent upgrade of the resources of container terminals, an efficient and smooth operation mechanism can be established, and the operational efficiency of a terminal can be effectively improved under the premise of low cost [4]. With the continuous advancement of technology, container terminals will continue to grow in scale and become automated and digitally managed. At present, few container terminals in China, such as the Xiamen Yuanhai Terminal and Shanghai Yangshan Port Terminal, implement unmanned and fully automated operations. Several container terminals implement a semi-automatic operation. For example, Ningbo Zhoushan Port implements the remote-control transformation of gantry cranes at Ningbo Meishan Terminal. However, most container terminals are still operated manually [5]. The three major operations of a container terminal include loading and unloading operations, horizontal transportation, and storage operations. The equipment use for these operations of (semi-) automated container terminals are (semi-) automated quay cranes, AGV guided vehicles, and (semi-) automated gantry cranes, respectively. The equipment used for the operations of non-automated container terminals are quay cranes, container trucks, and gantry cranes. The two modes of operation mainly differ in equipment used in the horizontal transportation system.

Research on the container truck dispatching problem has gradually shifted from static scheduling strategy to dynamic scheduling strategy. The dynamic scheduling strategy comprehensively considers the operational requirements of quay and gantry cranes, and it is more consistent with the actual situation. Yan and Tao [6] proposed the dynamic properties of container truck work and built a dynamic container truck optimization model for solving the optimal travel path of container trucks. To satisfy the customer's work requirements, Han [7] designed a mathematical programming model for minimizing the number of container trucks in the terminal. These studies mainly aim to solve the travel path or configuration quantity of container trucks for horizontal transportation operations during the terminal production operation. However, the rest of the operations at the terminal, that is, the equipment allocation of loading and unloading operations and storage operations, is not considered. Thus, the complete operation process of the container terminal can be reflected. Zeng and Yang [8] established a dynamic model for container truck dispatching to minimize the waiting time of the quay cranes and used the Q-learning algorithm to solve the problem. Ji et al. [9] also constructed a container truck dispatching model with the same goal. The difference is that their model incorporates the idea of loading and unloading synchronization, which can provide solutions for the optimization of the container truck travel path. Zeng and Yang
[10] analyzed and modeled the unloading operations of container terminals and solved the model with a two-stage Tabu search. Xu and Tao [11] used multi-objective fuzzy decision and an analytic hierarchy process to solve the optimal travel path of container trucks. Wang et al. [12] considered the container vehicle routing problem with a working time constraint load and solved the problem through a hybrid Tabu search. These studies simplify the influencing factors of container truck dispatching, but these container truck dispatching models have certain practical limitations.

As a connected transportation tool for terminal loading and unloading operations, horizontal transportation, and storage operations, container trucks can achieve the objectives of efficient operation of terminals while working in conjunction with other terminal resources. For example, Liang and Shen [13] established a model for determining the shortest transportation time of container trucks by studying the influence of quay cranes on container trucks and then calculated the solution using the genetic algorithm and particle swarm optimization. Shao [14] conducted an optimization study on the imported and exported container operations of rubber-tired gantry cranes in the yard on the basis of the container truck feedback reservation mechanism. In the above study, although the impact of other terminal resources on container truck scheduling is considered comprehensively, it is still based on static assumptions. In this regard, to improve the feasibility of this model in actual operation, this paper established a more comprehensive container truck scheduling model wherein the operational requirements of ship berths, quay cranes, and container trucks are considered on the basis of the dynamic scheduling strategy; the imported and exported transportation task scheduling system of container trucks are regarded as a total system based on the coordinated scheduling strategy; and the complete terminal operation process is considered.

\section{Analysis of Container Truck Dispatching Problem in Container Terminal}

\subsection{Layout and Basic Composition of Container Terminal}

A container terminal is a hub of activities, that is, the connection point, transit point, relocation, and intermodal transportation of international container maritime and land transportation. It is a port place that specializes in providing container ships to park and perform container loading and unloading operations [15].

The operation content of container terminals, can be classified into four major resources, namely, loading and unloading, horizontal transportation, storage, and other resources [16, 17]. In Figure 1, Area A represents the loading and unloading resources, which are mainly responsible for the loading and unloading of containers at container terminals. Area B is a storage resource and a place for various containers to be stacked. Area $\mathrm{C}$ is the other resource 
area of the container terminal besides the loading, unloading, and storage resource area. It is responsible for the handover of full container load (FCL) and less container load (LCL), the inspection of containers, comprehensive office, maintenance, and parking of vehicles. The horizontal transportation resource connects Areas A, B, and C and transports the containers in each area, including internal and external container trucks, straddle carriers, and forklifts.

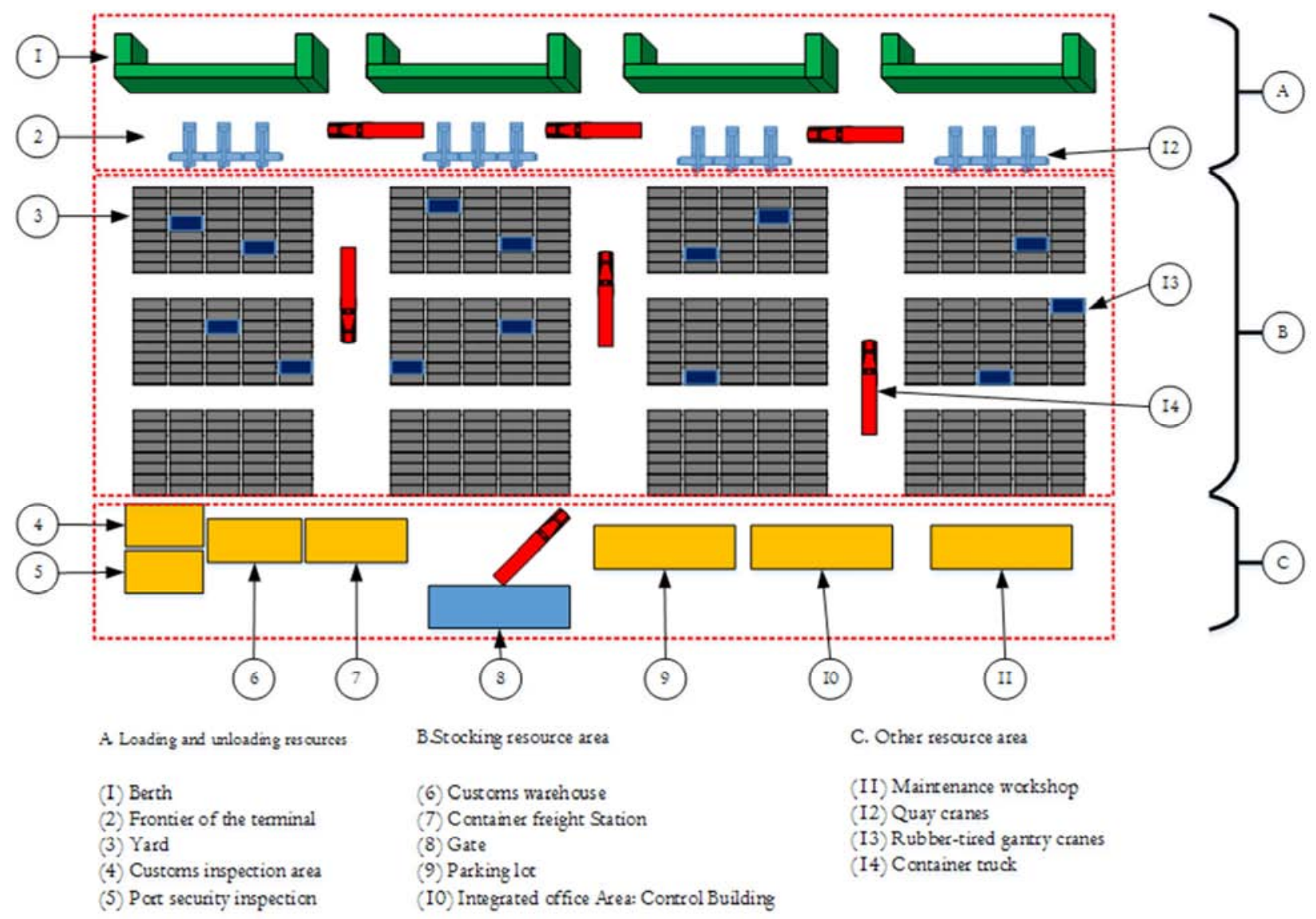

Figure 1. Layout and basic composition of container terminal.

\subsection{Dispatching Mode of Container Trucks at Container Terminals}

The template is used to format your paper and style the text. All margins, column widths, line spaces, and text fonts are prescribed; please do not alter them. You may note peculiarities. For example, the head margin in this template measures proportionately more than is customary. This measurement and others are deliberate, using specifications that anticipate your paper as one part of the entire publication, and not as an independent document. Please do not revise any of the current designations.

\subsubsection{Traditional “Operations Path” Dispatching Mode}

Figure 2 shows the loading and unloading processes that were categorized according to the equipment used in the three major operations of a container terminal (loading and unloading operation, horizontal transportation, and storage operation). In the imported container unloading operation, the container is unloaded from the ship through the quay cranes after the ship arrives at the terminal and then transported to the yard for storage by the internal container truck. After receiving the bill of lading from the owner, the yard arranges the yard crane to find the corresponding container and transport it to the designated place of the cargo owner through an external container truck. In the loading operation of the exported container, the external container truck transports the exported container to the yard in front of the dock, and the yard crane unloads the container from the external container truck, thereby completing the delivery of the container. Then, the internal container truck will transport the corresponding exported container to the working quay cranes according to the shipping plan. Finally, the quay cranes complete the exported container loading operation at the frontier of the terminal.

The traditional "operations path" dispatching mode for container trucks in container terminals refers to several pre-designated container trucks that arrange a fixed transportation operation team to serve the designated quay cranes to complete loading and unloading tasks. The mode form is shown in Figure 3. 


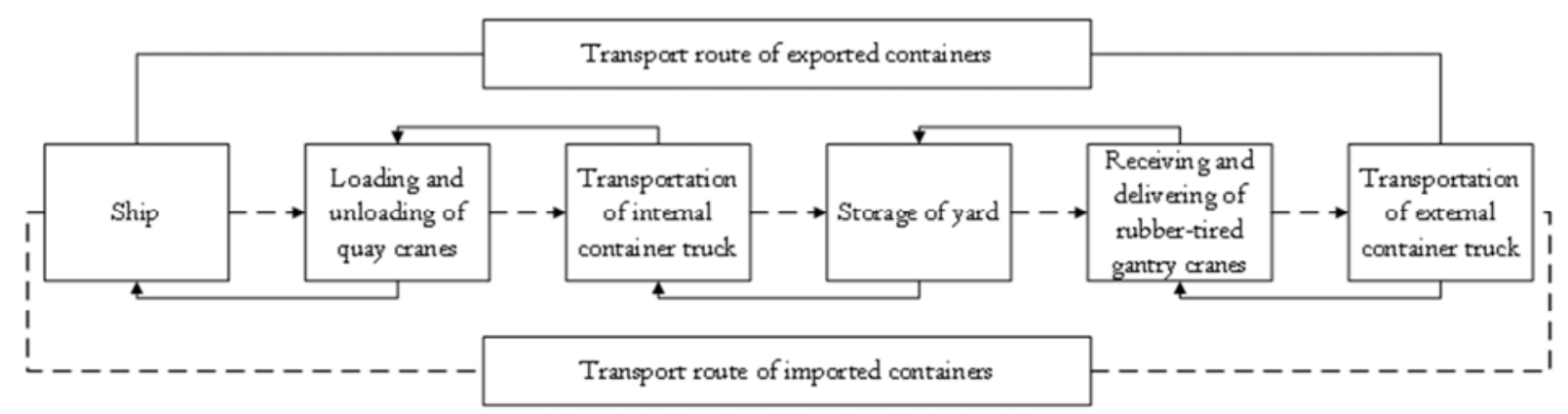

Figure 2. Mixing System of quay cranes, rubber-tired gantry cranes, and container trucks.

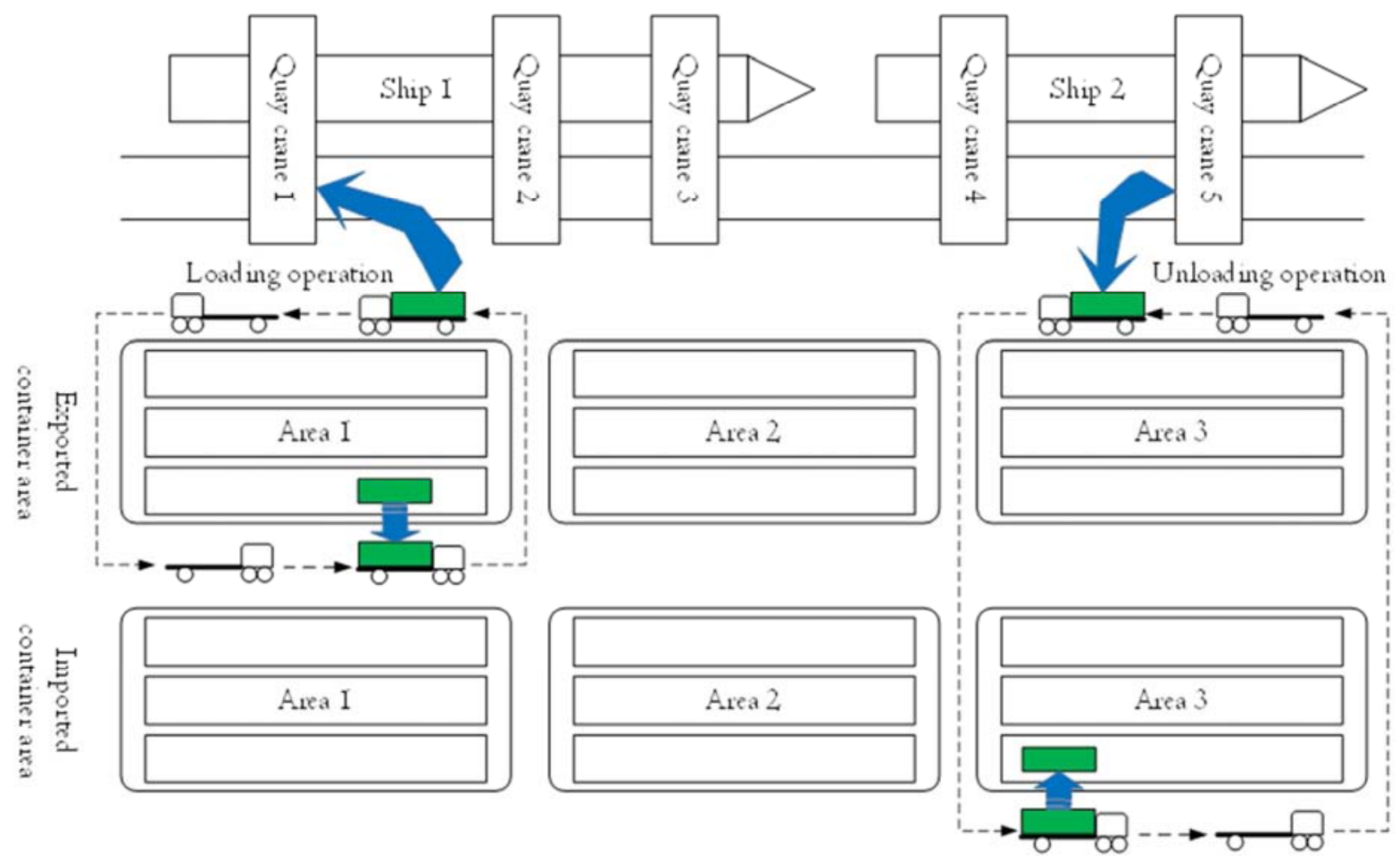

Figure 3. Traditional "operations path" scheduling mode for container trucks in container terminals.

\subsubsection{Coordinated Dispatching Mode of Container Trucks}

Collaboration refers to the process of combining different resources or individuals to work together and achieve the same goal. In this paper, the coordinated dispatching of container trucks is as follows: Container trucks that are only responsible for the transport operations of the exported containers (transport operations before shipment) and those that are only responsible for the transport operations of the imported containers (transport operations after unloading) are coordinated. The container truck transportation tasks are dispatched as a subsystem. The dispatching of the container truck unloading task is treated as another subsystem. Two subsystems are combined to form a system. Meanwhile, the operation scheduling plans of different operating equipment under the same operation task must be coordinated. This way, the shortest time of ship operation in a port, high operating efficiency of each working machine, and global optimization of terminal operation are achieved.
Container trucks only perform one task, serve one quay crane, and has one operation direction and route operation. The coordinated dispatching of container trucks can effectively prevent the unreasonable local optimization of container trucks in the traditional operation mode. The coordinated dispatching of container trucks can integrate the two-way operation requirements of container terminal loading and unloading to maximize the use of the operating equipment. Therefore, operational planning should be geared toward ensuring the overall efficiency of container terminal operations.

The basic concept of coordinated dispatching of container trucks is different from the traditional one-way operation dispatching mode. In the coordinated dispatching mode of container trucks in container terminals, container trucks or gantry cranes can be freely dispatched to serve any quay crane and task, as shown in Figure 4. 


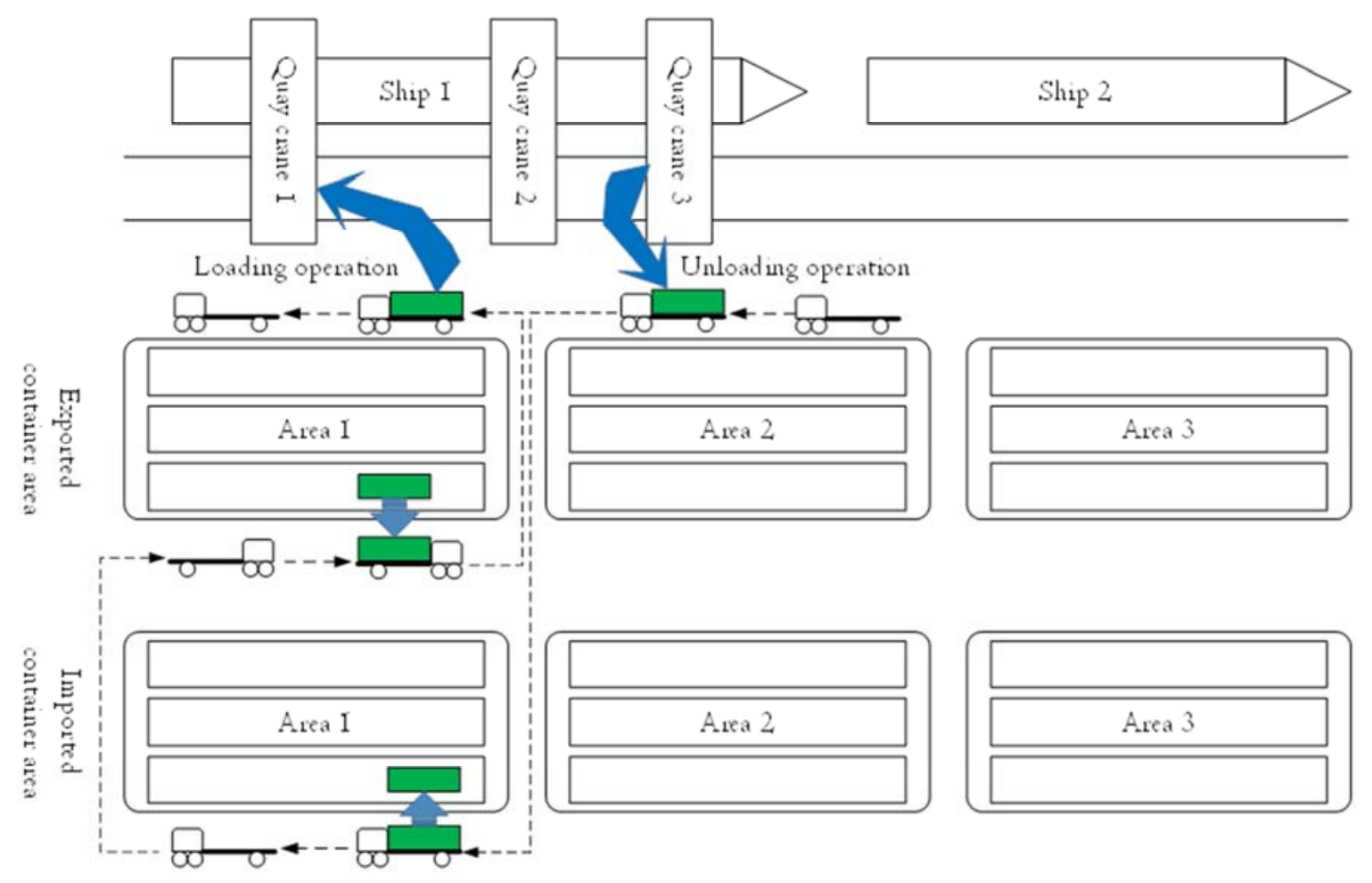

Figure 4. Cooperative scheduling mode of container trucks in container terminals.

\section{Construction of Coordinated Dispatching Mode of Container Trucks}

\subsection{Description of Problem}

The container truck dispatching model under the cooperative scheduling strategy is different from the traditional container truck scheduling in that it can serve multiple quay cranes in the same operating period and can be loaded and unloaded in one operating circuit. The goal of the model is based on the shortest working time of the ship in the port. First, by changing the position of the ship and the number of quay cranes, the shortest combination of the quay cranes' operation times is obtained. Then, according to the determined ship docking position, the operating quay cranes, and the position of the container in the yard, the operating route and time of the container truck can be solved. Finally, the container truck dispatching plan that satisfies the goal is obtained.

\subsection{Construction of Mode}

\subsubsection{Assumptions and Notations of Mode}

For formulation of the coordinated dispatching mode of container trucks, the following assumptions are made:

a. According to the ship's loading and unloading container plan, the number of loading and unloading containers for ships arriving at the port is known.

b. After the ship is docked at the berth, no berth movement occurs.

c. After the ship is docked at the berth, the quay cranes begin to serve, and the operations between the quay cranes do not interfere with each other.

d. Each ship can be served only once by the quay cranes.

e. The allowed minimum and maximum numbers of quay cranes can be satisfied when each ship is in operation.

$\mathrm{f}$. The berth is continuous, and the berth length is greater than the length of the ship, that is, the ship entering the port terminal can stop at the berth.

g. Each ship has the best position for berthing. If the ship deviates from this position, then the operating times of the quay cranes and the container trucks will be affected.

h. After the ship is docked at the berth, the transport time of the container truck between the frontier of the terminal and each container yard area is known.

i. Given the fast speed of container trucks, the distance traveled by container trucks between quay cranes is negligible.

j. During a certain period, the equipment can be dispatched for loading and unloading operations at the container terminal.

To formulate the coordinated dispatching mode of container trucks, let us define the following notations, including the parameters and decision variables.

Parameter design:

a. $L$ : Total length of terminal shoreline.

b. $s$ : Ships that have not yet docked and have been docked at the berth, where $s \in\{1,2, \ldots, S\}$ and $s_{1}, s_{2}, \ldots, s_{S}$.

c. $Q$ : Quay cranes, where $Q \in\left\{1,2, \ldots, n_{Q}\right\}$.

d. $n_{s Q}^{\max }$ : Maximum number of quay cranes allowed to be configured for each ship.

e. $n_{s Q}^{\min }$ : Minimum number of quay cranes allowed to be configured for each ship. 
f. $\eta$ : Single container loading and unloading efficiency of each quay crane; the unit is box/set per minute.

g. $P_{s}^{O}$ : Best docked position of the ship $(s)$ based on the left end of the ship.

h. $\Delta P_{s}$ : Deviation between the actual docked position and the optimal docked position of the ship $(s)$ that affects the transport distance of the container truck from the quay crane to the yard.

i. $\alpha$ : The amplifying coefficient of the deviation, that is, the degree to which the residence time of the ship $(s)$ in the port is affected by one unit deviating from the optimal docked position.

j. $t_{a}^{s}$ : Arrival time of the ship $(s)$ at the port.

k. $t_{w}^{s}$ : Starting time of operation of the ship $(s)$.

1. $t_{d}^{s}$ : Departure time of the ship $(s)$ from the port.

$\mathrm{m} . t_{O}^{s}$ : Transportation time of the container truck, which is affected by the docking position of the ship and the path of the container truck.

n. $N_{s}^{L}$ : Number of loading containers for the ship $(s)$ docked at the port.

o. $N_{s}^{U}$ : Number of unloading containers for the ship $(s)$ docked at the port.

p. $n_{s}^{U}$ : Number of imported container yard areas planned for unloading when the ship $(s)$ is docked at the port.

q. $n_{s}^{L}$ : Number of exported container yard areas planned for loading when the ship $(s)$ is docked at the port.

r. $U_{s}^{b}$ : Number of containers planned to be stored in the $a^{\text {th }}$ imported container yard area when the ship $(s)$ is docked at the port, where $a \in\left\{1,2, \ldots, n_{s}^{U}\right\}$.

s. $L_{s}^{b}$ : Number of containers planned to be extracted from the $b^{\text {th }}$ exported container yard area when the ship $(s)$ is docked at the port, where $b \in\left\{1,2, \ldots, n_{s}^{L}\right\}$.

t. $t_{s a}$ : Transportation time of container truck from the ship $(s)$ to the $a^{\text {th }}$ imported container yard area.

u. $t_{a b}$ : Transportation time of container truck from the $a^{\text {th }}$ imported container yard area to the $b^{\text {th }}$ exported container yard area.

v. $t_{b s}$ : Transportation time of container truck from the $b^{\text {th }}$ exported container yard area to the ship $(s)$.

w. $t_{b a}$ : Transportation time of container truck from the $b^{\text {th }}$ exported container yard area to the $a^{\text {th }}$ imported container yard area.

x. $t_{a s}$ : Transportation time of container truck from the $a^{\text {th }}$ imported container yard area to the ship $(s)$.

y. $Z$ : Infinite positive integer.
Decision variables:

a. $x_{p q}^{s}=1$, if Ship $(s)$ starts to berth from $(p, q)$, where $\mathrm{p}$ is the set of berthing points of Ship $(s)$ and $p \in\{1,2, \ldots, L\}$, and $q$ is the set of berthing time points of Ship $(s)$ and $q \in\{1,2, \ldots, K\} ; x_{p q}^{s}=0$, if Ship $(s)$ is not berthing.

b. $y_{p q}^{s}=1$, if the number of quay cranes is $Q_{q}^{S}$ when Ship $(s)$ is berthing at $(p, q) ; y_{p q}^{s}=0$, if Ship $(s)$ is not berthing.

c. $Q_{q}^{s}>0$, if the efficiency of quay cranes for operating a single container $\eta=1$, where $Q_{q}^{s}$ is the number of quay cranes when Ship $(s)$ is berthing at time points $q$ and $Q_{q}^{s} \in\{1,2, \ldots, n\} ; Q_{q}^{s}=0$, if $\eta=0$ and no quay cranes are allocated.

Given that container trucks only transport one container at a time, the number of transportations of container trucks in each link is equal to the number of containers transported. The relevant parameters are defined as follows:

a. $H_{a s}$ : Number of transportations of container trucks from the ship $(s)$ to the $a^{\text {th }}$ imported container yard area.

b. $H_{a b}$ : Number of transportations of container trucks from the $a^{\text {th }}$ imported container yard area to the $b^{\text {th }}$ exported container yard area.

c. $H_{b s}$ : Number of transportations of container trucks from the $b^{\text {th }}$ exported container yard area to the ship $(s)$.

d. $H_{\text {sas }}$ : Number of transportations of container trucks from the ship $(s)$ for carrying containers to the $a^{\text {th }}$ imported container yard area for unloading of containers and the return to the ship $(s)$.

e. $H_{b s b}$ : Number of transportations of container trucks from the $b^{\text {th }}$ exported container yard area for carrying containers to the ship $(s)$ for loading of containers and the return to the $b^{\text {th }}$ exported container yard area.

f. $H_{\text {sabs }}$ : Number of transportations of container trucks from the ships $(s)$ for carrying containers to the $a^{\text {th }}$ imported container yard area for unloading of containers, to the $b^{\text {th }}$ exported container yard area for loading of containers, and the return to the ships $(s)$.

\subsubsection{Mode Design}

Objective function:

The shortest operation time of the terminal $=\min$ (berthing time of ship + transportation time of container truck)

$$
T=\min \left[\sum_{s=1}^{S} \sum_{p=1}^{L} \sum_{q=1}^{K} x_{p q}^{s}\left(1+\alpha \Delta p_{s}\right)\left(t_{d}-t_{a}\right)+\sum_{s=1}^{S} \sum_{p=1}^{L} \sum_{q=1}^{K} y_{p q}^{s} t_{o}^{s}\right]
$$

Constraints:

(1) Berthing time of ship:

a. After the ship is docked at the berth, no berth movement occurs, and each ship can be served only once by the quay cranes. Assumptions (b) and (d) are satisfied.

$$
\sum_{p=1}^{L} \sum_{q=1}^{K} x_{p q}^{s}=1, \quad \forall s \in S
$$

b. At location $p$ in the terminal, only one ship is berthing at time $q$, and this ship can be served only once by the quay cranes. Assumptions (d) is satisfied. 


$$
\begin{aligned}
y_{p q}^{s} \leq 1, p & \in\{1,2, \ldots, L\}, \\
q & \in\{1,2, \ldots, K\}, \forall s \in S
\end{aligned}
$$

c. The total length of the berths of all docked ships at a given time is less than the total length of the terminal shoreline.

$$
\sum_{s=1}^{S} P_{s} \leq L, \forall s \in S
$$

d. At any time $q$, the number of quay cranes that are configured for all ships is less than the total number of quay cranes.

$$
\sum_{q=1}^{K} Q_{q}^{s} \leq n_{Q}, \quad \forall s \in S
$$

e. At any time q, the number of quay cranes that are configured for each ship is within the number of quay cranes that can be configured for operation.

$$
n_{s Q}^{\min } \leq Q_{q}^{s} \leq n_{s Q}^{\max }, \quad \forall s \in S
$$

f. The berthing time of a ship is the operation time of quay cranes. When the operation of quay cranes is completed, the loading and unloading operation of the ship is completed. Then, the ship leaves the port. The operation time of quay cranes is equal to the total number of containers to be loaded and unloaded divided by the operational efficiency of a single container for all quay cranes.

$$
t_{d}^{s}-t_{a}^{s}=\frac{N_{s}^{L}+N_{s}^{U}}{2 \eta \sum_{s=1}^{S} Q_{q}^{s}}
$$

g. $\Delta P_{s}$ is the difference between the actual position of the ship for berthing and the best position of the ship for berthing. The greater the difference, the greater the distance from the ship to the imported and exported container yard area and the longer the working time of the quay cranes and the container trucks.

$$
\Delta P_{s}=\left|P_{s}-P_{s}^{o}\right|
$$

(2) Transportation time of container truck:

a. Container trucks have three modes of transport. In the first type, container trucks only carry imported containers from the ship to an imported container yard area and then return to their respective ships. In the second type, container trucks only carry exported containers from an exported container yard area to their respective ships and then return to the exported container yard area. The last method is based on the cooperative scheduling strategy in which container trucks carry imported containers from their respective ships to an imported container yard area and then go to an exported container yard area and carry exported containers to the ships. Therefore, the transportation time of container trucks includes the transportation time of these three types.

$$
t_{o}^{s}=\sum_{a=1}^{n_{s}^{U}} H_{s a s}\left(t_{s a}+t_{a s}\right)+\sum_{b=1}^{n_{s}^{L}} H_{b s b}\left(t_{b s}+t_{s b}\right)+\sum_{a=1}^{n_{s}^{U}} \sum_{b=1}^{n_{s}^{L}} H_{s a b s}\left(t_{s a}+t_{a b}+t_{b s}\right)
$$

b. Based on the cooperative scheduling strategy, the transportation link of container trucks consists of three links: "ship-imported container yard area," "imported container yard area-exported container yard area," and "exported container yard area-ship." To complete the integral transportation cycle of "ship-imported container yard area-exported container yard area-ship," the number of transportations of these three links must be the same, and the number of transportations should be the minimum number of containers waiting to be loaded on a ship in port and the number of containers waiting to be unloaded on a ship in port.

$$
\sum_{a=1}^{n_{s}^{U}} H_{s a}=\sum_{a=1}^{n_{s}^{U}} \sum_{b=1}^{n_{s}^{L}} H_{a b}=\sum_{b=1}^{n_{s}^{L}} H_{b s}=\min \left\{N_{s}^{U}, N_{s}^{L}\right\}
$$

c. If the number of containers to be unloaded is greater than the number of containers to be loaded, then the unloading operation of the "ship-imported container yard area-ship" is implement by the container truck for the excess to-be-unloaded containers. If the number of containers to be loaded is greater than the number of containers to be unloaded, the loading operation of the "exported container yard area-ship-exported container yard area" is implement by the container truck for the excess boxes to be packed.

$$
\begin{aligned}
& \sum_{a=1}^{n_{s}^{U}} H_{s a s}=\max \left\{N_{s}^{U}-N_{s}^{L}, 0\right\} \\
& \sum_{b=1}^{n_{s}^{L}} H_{b s b}=\max \left\{N_{s}^{L}-N_{s}^{U}, 0\right\}
\end{aligned}
$$

d. In the operations of the "ship-imported container yard area-ship" and "ship-imported container yard area-exported container yard area-ship," the number of containers to be unloaded is equal to the number of containers to be unloaded in a ship $(s)$ docked at a port, and it is the same as the number of containers to be unloaded in all imported container yard area in a ship 
$(s)$ docked at a port. In the operations of the "exported container yard area-ship-exported container yard area" and "ship-exported container yard area-imported container yard area-ship," the number of containers to be loaded is equal to the number of containers to be loaded in a ship $(s)$ docked at a port, and it is also the same as the number of containers to be loaded in all exported container yard area in a ship $(s)$ docked at a port.

$$
\begin{aligned}
& \sum_{a=1}^{n_{s}^{U}} H_{s a s}+\sum_{a=1}^{n_{s}^{U}} \sum_{b=1}^{n_{s}^{L}} H_{s a b s}=N_{s}^{U}=\sum_{a=1}^{n_{s}^{U}} U_{s}^{a} \\
& \sum_{b=1}^{n_{s}^{L}} H_{b s b}+\sum_{a=1}^{n_{s}^{U}} \sum_{b=1}^{n_{s}^{L}} H_{s a b s}=N_{s}^{L}=\sum_{b=1}^{n_{s}^{L}} L_{s}^{b}
\end{aligned}
$$

e. The number of containers unloaded to the $a^{\text {th }}$ imported container yard area in ships $(s)$ docked at a port is the same as the number of planned stacking containers in the imported container yard area, and the number of containers loaded from the $b^{\text {th }}$ exported container yard area in ships $(s)$ docked at a port is consistent with the number of planned extraction containers in the exported container yard area.

$$
\begin{aligned}
& H_{s a s}+H_{s a}=U_{s}^{a}, \quad a \in\left\{1,2, \cdots, n_{s}^{U}\right\} \\
& H_{b s b}+H_{b s}=L_{s}^{b}, \quad b \in\left\{1,2, \cdots, n_{s}^{L}\right\}
\end{aligned}
$$

f. The number of containers unloaded from ship $(s)$ to the $a^{\text {th }}$ imported container yard area by a container truck is the same as the number of containers planned to be stored in the $a^{\text {th }}$ imported container yard area, and the number of containers loaded from the $b^{\text {th }}$ exported container yard area to a ship $(s)$ by a container truck is the same as the number of containers planned to be extracted in the $b^{\text {th }}$ exported container yard area.

$$
\begin{aligned}
& N_{s}^{U}=U_{s}^{a}, \quad a \in\left\{1,2, \cdots, n_{s}^{U}\right\} \\
& N_{s}^{L}=L_{s}^{b}, \quad b \in\left\{1,2, \cdots, n_{s}^{L}\right\}
\end{aligned}
$$

\subsection{Model Solving Method}

The objective function is mainly composed of two parts. One is the zero-one integer programming of the decision variable, and the other part is the linear programming of the transportation time calculation. Transportation time calculation is divided into two stages. The first stage solves the quay cranes operation time of the ship docked at the port by changing the stopping position of the inbound ship and the serial number and quantity of the allocated quay cranes. The second phase is based on the combined solution of the first phase to determine the transportation path of container truck and find the shortest container truck transportation operation time. The evolutionary algorithm in Excel solver is used to solve this model.

This study aims to dispatch the arrival ships in a certain period. The evolutionary algorithm can be used to solve the positions of many potential ships docked and the allocation planning of quay cranes. Therefore, the evolutionary algorithm is used to obtain the solution for the model.

\section{Case Analysis - Taking Humen Port Container Terminal as an Example}

\subsection{Description of Humen Port}

Dongguan Humen Port International Container Terminal is a non-automated container terminal located at the mouth of Pearl River. It is the middle ground of the development axis of Guangzhou, Dongguan, Shenzhen, and Hong Kong and is the core position of the Pearl River Delta economic zone [18]. Given the strategic position of Humen Port, the state and local governments have vigorously supported Humen Port in building a large-scale deep-water container terminal berth. In the 2017 domestic port container terminal appraisal ranking, Dongguan Humen Port International Container Terminal is respectively ranked 9th and 14th in the "2017 China the average efficiency of single handling ship reaches more than $30 \mathrm{M} / \mathrm{H}$ " and "2017 China the big vessel rate reaches more than $100 \mathrm{M} / \mathrm{H}$ " [19]. The loading and unloading efficiency of the container terminal of Humen Port in Dongguan has certain advantages and a potential for further improvement. Therefore, the container terminal of Humen Port is selected as a case study for data testing. The basic data mainly includes the facilities and equipment of the front of the terminal, the production operation information, and the information of the container truck and the yard.

\subsubsection{Basic Information of the Front of the Terminal}

This paper refers to the actual situation of the container terminal of Humen Port in Dongguan. The basic data and production operation information of the front of the terminal are as follows.

The total length of the shoreline of Humen Port Container Terminal is $678 \mathrm{~m}$, and the maximum water depth at the front of the terminal is $14.3 \mathrm{~m}$. Two 50,000-ton multi-purpose professional container berths exist. The terminal has a total area of $485,000 \mathrm{~m}^{2}$ and is equipped with six panama quayside container gantry cranes [20].

During the 24-hour operation period, five ships are assumed entering the port at the container terminal. The arrival time, the docking position of the ship, the number of containers to be loaded, the number of containers to be unloaded, and the number of imported and exported container yard areas are shown in Table 1. The quay cranes can be used for double container operation, that is, the quay cranes can load and unload two 20-ft containers at the same time, and their loading and unloading capacity is $60 \mathrm{TEUs} /$ hour. If the ship deviates 
from the initial stopping position, the effect of one tenth of each distance unit deviating from the optimal stop position is enlarged, that is, the amplifying coefficient of the deviation $(\alpha)$ is 0.1 .

Table 1. Information of inbound ship.

\begin{tabular}{|c|c|c|c|c|c|}
\hline Serial number of ships & $\mathbf{S}_{1}$ & $\mathbf{S}_{2}$ & $\mathbf{S}_{3}$ & $\mathbf{S}_{4}$ & $\mathbf{S}_{5}$ \\
\hline Arrival time & $3: 00$ & $7: 00$ & $9: 30$ & $16: 00$ & $19: 00$ \\
\hline Initial stop position & 1 & 1 & 339 & 339 & 1 \\
\hline Number of containers to be loaded & 220 & 260 & 300 & 450 & 180 \\
\hline Number of containers to be unloaded & 200 & 300 & 150 & 400 & 100 \\
\hline Minimum number of quay cranes & 2 & 2 & 2 & 2 & 2 \\
\hline Maximum number of quay cranes & 4 & 4 & 3 & 3 & 4 \\
\hline
\end{tabular}

Note: Data is based on the assumptions of the actual situation of the container terminal in Humen Port, Dongguan.

\subsubsection{Information of Container Truck and Yard}

The yard of Humen Port Container Terminal can accommodate 27,000 TEUs, and Humen Port Container Terminal is equipped with 20 gantry cranes, 9 imported container yard areas $\left(\mathrm{U}_{1}, \mathrm{U}_{2}, \ldots, \mathrm{U}_{9}\right)$, and 9 exported container yard areas $\left(\mathrm{L}_{1}, \mathrm{~L}_{2}, \ldots, \mathrm{L}_{9}\right)$ [20]. The number of containers to be loaded and unloaded is relatively known, as shown in Table 2. The distance between the berths of Humen Port Container Terminal and each imported and exported container yard area is shown in Table 3, and the distance between the imported and exported container yard areas of Humen Port Container Terminal is shown in Table 4.

Container terminal container truck transportation is mainly composed of two parts: the berth and imported and exported container yard areas and the horizontal transportation between the imported and exported container yard areas. The speed of container trucks varies according to the load capacity. According to the commercial operation speed of container trucks, the traveling speeds of the container truck are $80 \mathrm{~km} / \mathrm{h}$ when overloaded and $100 \mathrm{~km} / \mathrm{h}$ when empty. Given the distance between the berths of the container terminals and the imported and exported container yard areas and the distance between the imported and exported container yard areas are known, the transportation time information of the container trucks in each area can be ascertained (see Tables 5, 6, 7, and 8).

Table 2. Distribution of the number of containers to be loaded and unloaded in the container yard areas of the ships in port (unit: box).

\begin{tabular}{|c|c|c|c|c|c|c|c|c|c|c|}
\hline & $\mathbf{L}_{1}$ & $\mathbf{L}_{2}$ & $\mathbf{L}_{3}$ & $\mathbf{L}_{4}$ & $\mathbf{L}_{5}$ & $\mathbf{L}_{6}$ & $\mathbf{L}_{7}$ & $\mathbf{L}_{8}$ & $\mathbf{L}_{9}$ & Total number of containers to be loaded \\
\hline $\mathrm{S}_{1}$ & 60 & 80 & 30 & 50 & 0 & 0 & 0 & 0 & 0 & 220 \\
\hline $\mathrm{S}_{2}$ & 0 & 0 & 80 & 90 & 90 & 0 & 0 & 0 & 0 & 260 \\
\hline $\mathrm{S}_{3}$ & 0 & 60 & 80 & 70 & 40 & 50 & 0 & 0 & 0 & 300 \\
\hline $\mathrm{S}_{4}$ & 0 & 0 & 0 & 0 & 100 & 50 & 90 & 130 & 80 & 450 \\
\hline $\mathrm{S}_{5}$ & 0 & 0 & 0 & 0 & 0 & 0 & 70 & 50 & 60 & 180 \\
\hline & $\mathbf{U}_{1}$ & $\mathbf{U}_{2}$ & $\mathbf{U}_{3}$ & $\mathbf{U}_{4}$ & $\mathbf{U}_{5}$ & $\mathrm{U}_{6}$ & $\mathbf{U}_{7}$ & $\mathbf{U}_{8}$ & $\mathrm{U}_{9}$ & Total number of containers to be unloaded \\
\hline $\mathrm{S}_{1}$ & 90 & 50 & 60 & 0 & 0 & 0 & 0 & 0 & 0 & 200 \\
\hline $\mathrm{S}_{2}$ & 0 & 70 & 80 & 100 & 50 & 0 & 0 & 0 & 0 & 300 \\
\hline $\mathrm{S}_{3}$ & 0 & 0 & 0 & 0 & 40 & 40 & 70 & 0 & 0 & 150 \\
\hline $\mathrm{S}_{4}$ & 0 & 90 & 70 & 100 & 30 & 110 & 0 & 0 & 0 & 400 \\
\hline $\mathrm{S}_{5}$ & 0 & 0 & 0 & 0 & 0 & 30 & 50 & 20 & 0 & 100 \\
\hline
\end{tabular}

Note: Data is based on the assumptions of the actual situation of the container terminal in Humen Port, Dongguan.

Table 3. Distance between the berths of Humen Port Container Terminal and various imported and exported container yard areas (Unit: meter).

\begin{tabular}{lllll}
\hline Exported container yard areas & Berth 1 & Berth 2 & Imported container yard areas & Berth 1 \\
\hline $\mathrm{L}_{1}$ & 80 & 419 & $\mathrm{U}_{1}$ & 408 \\
$\mathrm{~L}_{4}$ & 184 & 523 & $\mathrm{U}_{4}$ & 512 \\
$\mathrm{~L}_{7}$ & 288 & 627 & $\mathrm{U}_{7}$ & 747 \\
$\mathrm{~L}_{2}$ & 190 & 190 & $\mathrm{U}_{2}$ & 851 \\
$\mathrm{~L}_{5}$ & 294 & 294 & $\mathrm{U}_{5}$ & 518 \\
$\mathrm{~L}_{8}$ & 398 & 398 & $\mathrm{U}_{8}$ & 622 \\
$\mathrm{~L}_{3}$ & 419 & 80 & $\mathrm{U}_{3}$ & 726 \\
$\mathrm{~L}_{6}$ & 523 & 184 & $\mathrm{U}_{6}$ & 747 \\
$\mathrm{~L}_{9}$ & 627 & 288 & $\mathrm{U}_{9}$ & 726 \\
\hline
\end{tabular}

Note: Data is calculated based on the actual situation of the container terminal in Humen Port, Dongguan.

Table 4. Distance between imported and exported container yard areas of Humen Port Container Terminal (Unit: meter).

\begin{tabular}{lllllllll}
\hline & $\mathbf{L}_{\mathbf{1}}$ & $\mathbf{L}_{\mathbf{2}}$ & $\mathbf{L}_{\mathbf{3}}$ & $\mathbf{L}_{\mathbf{4}}$ & $\mathbf{L}_{\mathbf{5}}$ & $\mathbf{L}_{\mathbf{6}}$ & $\mathbf{L}_{\mathbf{7}}$ & $\mathbf{L}_{\mathbf{8}}$ \\
\hline $\mathrm{U}_{1}$ & 328 & 338 & 567 & 224 & 234 & 463 & 120 & 130 \\
$\mathrm{U}_{2}$ & 338 & 328 & 338 & 234 & 224 & 234 & 130 & 120 \\
\hline
\end{tabular}




\begin{tabular}{|c|c|c|c|c|c|c|c|c|c|}
\hline & $\mathbf{L}_{1}$ & $\mathbf{L}_{2}$ & $\mathbf{L}_{3}$ & $\mathbf{L}_{4}$ & $\mathbf{L}_{5}$ & $\mathbf{L}_{6}$ & $\mathbf{L}_{7}$ & $\mathbf{L}_{8}$ & L9 \\
\hline $\mathrm{U}_{3}$ & 567 & 338 & 328 & 463 & 234 & 224 & 359 & 130 & 120 \\
\hline $\mathrm{U}_{4}$ & 432 & 442 & 671 & 328 & 338 & 567 & 224 & 234 & 463 \\
\hline $\mathrm{U}_{5}$ & 442 & 432 & 442 & 338 & 328 & 338 & 234 & 224 & 234 \\
\hline $\mathrm{U}_{6}$ & 671 & 442 & 432 & 567 & 338 & 328 & 463 & 234 & 224 \\
\hline $\mathrm{U}_{7}$ & 536 & 546 & 775 & 432 & 442 & 671 & 328 & 338 & 567 \\
\hline $\mathrm{U}_{8}$ & 546 & 536 & 546 & 442 & 432 & 442 & 338 & 328 & 338 \\
\hline $\mathrm{U}_{9}$ & 775 & 546 & 536 & 671 & 442 & 432 & 567 & 338 & 328 \\
\hline
\end{tabular}

Note: Data is calculated based on the actual situation of the container terminal in Humen Port, Dongguan.

Table 5. Transportation time of container trucks between the berth and the exported container yard areas (unit: minute).

\begin{tabular}{lllll}
\hline \multirow{2}{*}{ Exported container yard areas } & Berth 1 & Berth 2 & Overload \\
\cline { 2 - 5 } & Empty drive & Overload & Empty drive & 0.314 \\
\hline $\mathrm{L}_{1}$ & 0.048 & 0.060 & 0.251 & 0.392 \\
$\mathrm{~L}_{4}$ & 0.110 & 0.138 & 0.314 & 0.470 \\
$\mathrm{~L}_{7}$ & 0.173 & 0.216 & 0.376 & 0.142 \\
$\mathrm{~L}_{2}$ & 0.114 & 0.142 & 0.114 & 0.220 \\
$\mathrm{~L}_{5}$ & 0.176 & 0.220 & 0.176 & 0.298 \\
$\mathrm{~L}_{8}$ & 0.239 & 0.298 & 0.239 & 0.060 \\
$\mathrm{~L}_{3}$ & 0.251 & 0.314 & 0.048 & 0.138 \\
$\mathrm{~L}_{6}$ & 0.314 & 0.392 & 0.110 & 0.216 \\
$\mathrm{~L}_{9}$ & 0.376 & 0.470 & 0.173 & \\
\hline
\end{tabular}

Note: Data is calculated based on the distance between the berth of the container terminal of Humen Port in Dongguan and the exported container yard area, and the speed of the empty and heavy load of the container truck.

Table 6. Transportation time of container trucks between the berth and the imported container yard areas (unit: minute).

\begin{tabular}{lllll}
\hline \multirow{2}{*}{ Imported container yard areas } & Berth 1 & & Berth 2 & Overload \\
\cline { 2 - 5 } & Empty drive & Overload & Empty drive & 0.560 \\
\hline $\mathrm{U}_{1}$ & 0.245 & 0.306 & 0.448 & 0.638 \\
$\mathrm{U}_{4}$ & 0.307 & 0.384 & 0.510 & 0.716 \\
$\mathrm{U}_{7}$ & 0.370 & 0.462 & 0.573 & 0.388 \\
$\mathrm{U}_{2}$ & 0.311 & 0.388 & 0.311 & 0.466 \\
$\mathrm{U}_{5}$ & 0.373 & 0.466 & 0.373 & 0.544 \\
$\mathrm{U}_{8}$ & 0.435 & 0.544 & 0.435 & 0.306 \\
$\mathrm{U}_{3}$ & 0.448 & 0.560 & 0.245 & 0.384 \\
$\mathrm{U}_{6}$ & 0.510 & 0.638 & 0.307 & 0.462 \\
$\mathrm{U}_{9}$ & 0.573 & 0.716 & 0.370 & \\
\hline
\end{tabular}

Note: Data is calculated based on the distance between the berth of the container terminal of Humen Port in Dongguan and the imported container yard area, and the speed of the empty and heavy load of the container truck.

\subsection{Results of Case Analysis}

\subsubsection{Steps of Solution}

The target value of this model is the operation time of the terminal and is composed of two parts: the operation time of the quay cranes when the ship is docked at the port and the transportation time of the container truck. Thus, these two operations should be solved. First, according to the arrival time of the ship, the initial stopping position of the ship is set, and then the number and the operation time of the quay cranes for each ship are obtained based on the constraints of the operation of the quay cranes. Then, according to the horizontal transportation times of the container truck between the berths and the imported and exported container yard areas and between the imported and exported container yard areas, the container truck travel path and the transportation time for the corresponding operation link are solved. Finally, the times of these two parts are added together, and the operation time of the ship (T) can be obtained. Next, the stopping position of the ship is changed, and the new operation time of the ship
$\left(T_{1}\right)$ is obtained at this new stopping position. If $T_{1}$ is less than $T$, then the position of the ship after the change is better than the original docking position, which shortens the operation time of the ship. By analogy, the previous operations are repeated to solve the shortest operation time of all ships for obtaining the optimal solution of the model. Figure 5 shows the solution flow of the model.

\subsubsection{Analysis Results}

In this paper, the relevant parameters of evolution in the model programming are set as follows: the convergence of the objective function is 0.0001 , the calculation duration is limited to $30 \mathrm{~s}$, and the overall size is 100 . To obtain the global optimal solution, the mutation rates are set to $0.75,0.075$, and 0.0075 . The evolution calculations are repeated 20 times at the three mutation rates, and the optimal solutions under the different mutation rates are compared to avoid the local optimal solution. In Figure 6, the optimal solutions at the three mutation rates are all stable at the same numerical level, that is, the target value obtained in this paper is the optimal solution. 


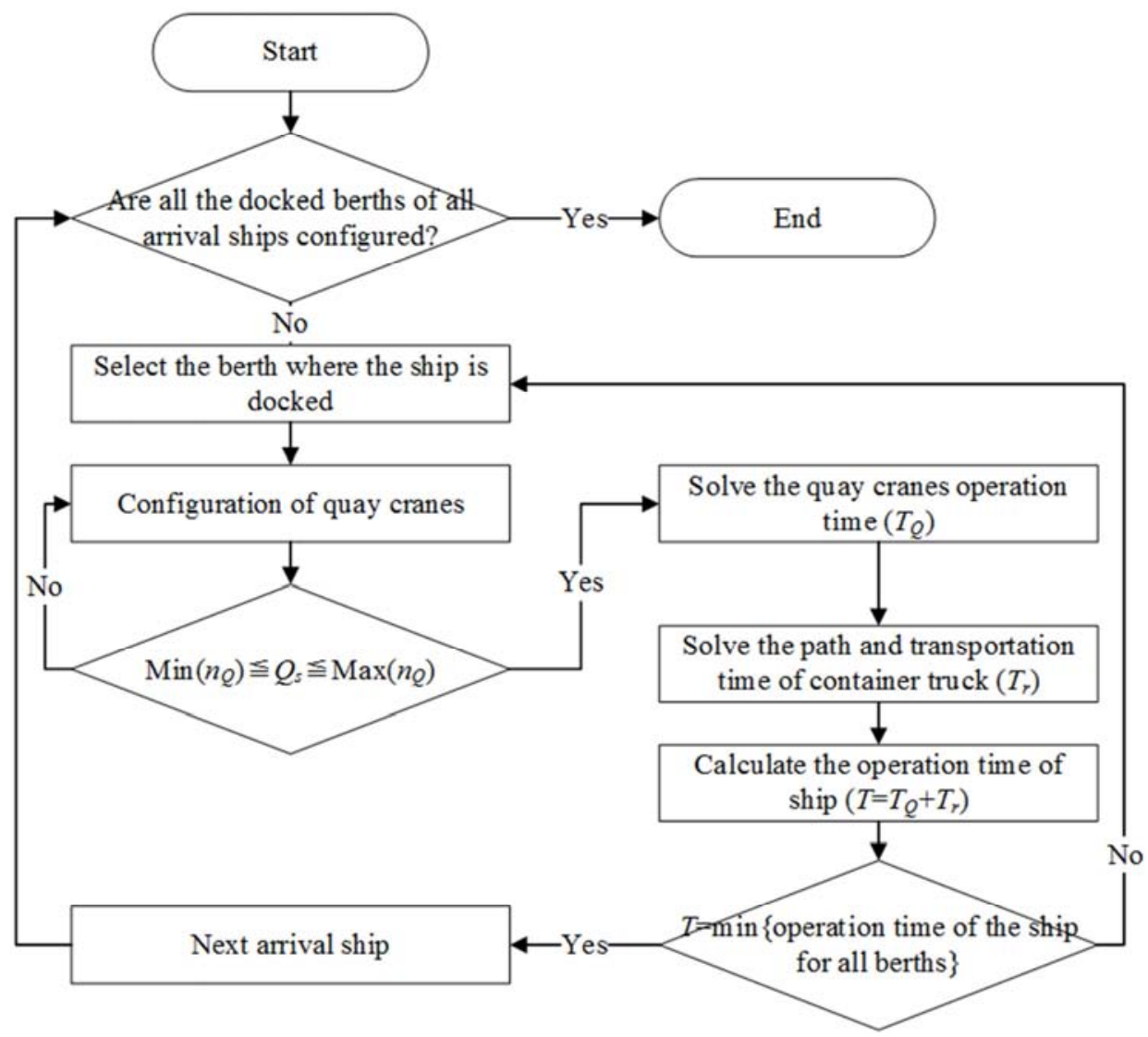

Figure 5. Flow chart for solving collaborative scheduling mode of container trucks in container terminal.

Table 7. Transportation time of empty container trucks between the imported and exported container yard areas (unit: minute).

\begin{tabular}{|c|c|c|c|c|c|c|c|c|c|}
\hline & $\mathbf{L}_{1}$ & $\mathbf{L}_{2}$ & $\mathbf{L}_{3}$ & $\mathbf{L}_{4}$ & $\mathbf{L}_{5}$ & $\mathbf{L}_{6}$ & $\mathbf{L}_{7}$ & $\mathbf{L}_{8}$ & $\mathrm{~L}_{9}$ \\
\hline $\mathrm{U}_{1}$ & 0.1968 & 0.2028 & 0.3402 & 0.1344 & 0.1404 & 0.2778 & 0.072 & 0.078 & 0.2154 \\
\hline $\mathrm{U}_{2}$ & 0.2028 & 0.1968 & 0.2028 & 0.1404 & 0.1344 & 0.1404 & 0.078 & 0.072 & 0.078 \\
\hline $\mathrm{U}_{3}$ & 0.3402 & 0.2028 & 0.1968 & 0.2778 & 0.1404 & 0.1344 & 0.2154 & 0.078 & 0.072 \\
\hline $\mathrm{U}_{4}$ & 0.2592 & 0.2652 & 0.4026 & 0.1968 & 0.2028 & 0.3402 & 0.1344 & 0.1404 & 0.2778 \\
\hline $\mathrm{U}_{5}$ & 0.2652 & 0.2592 & 0.2652 & 0.2028 & 0.1968 & 0.2028 & 0.1404 & 0.1344 & 0.1404 \\
\hline $\mathrm{U}_{6}$ & 0.4026 & 0.2652 & 0.2592 & 0.3402 & 0.2028 & 0.1968 & 0.2778 & 0.1404 & 0.1344 \\
\hline $\mathrm{U}_{7}$ & 0.3216 & 0.3276 & 0.465 & 0.2592 & 0.2652 & 0.4026 & 0.1968 & 0.2028 & 0.3402 \\
\hline $\mathrm{U}_{8}$ & 0.3276 & 0.3216 & 0.3276 & 0.2652 & 0.2592 & 0.2652 & 0.2028 & 0.1968 & 0.2028 \\
\hline $\mathrm{U}_{9}$ & 0.465 & 0.3276 & 0.3216 & 0.4026 & 0.2652 & 0.2592 & 0.3402 & 0.2028 & 0.1968 \\
\hline
\end{tabular}

Note: Data is calculated based on the distance between the imported and exported container yard areas of the container terminal of Humen Port in Dongguan and the empty speed of the container truck.

Table 8. Transportation time of heavy-duty container trucks between the imported and exported container yard areas (unit: minute).

\begin{tabular}{|c|c|c|c|c|c|c|c|c|c|}
\hline & $\mathbf{L}_{1}$ & $\mathbf{L}_{2}$ & $\mathbf{L}_{3}$ & $\mathbf{L}_{4}$ & $\mathbf{L}_{5}$ & $\mathbf{L}_{6}$ & $\mathbf{L}_{7}$ & $\mathbf{L}_{8}$ & $\mathrm{~L}_{9}$ \\
\hline $\mathrm{U}_{1}$ & 0.2460 & 0.2535 & 0.4253 & 0.1680 & 0.1755 & 0.3473 & 0.0900 & 0.0975 & 0.2693 \\
\hline $\mathrm{U}_{2}$ & 0.2535 & 0.2460 & 0.2535 & 0.1755 & 0.1680 & 0.1755 & 0.0975 & 0.0900 & 0.0975 \\
\hline $\mathrm{U}_{3}$ & 0.4253 & 0.2535 & 0.2460 & 0.3473 & 0.1755 & 0.1680 & 0.2693 & 0.0975 & 0.0900 \\
\hline $\mathrm{U}_{4}$ & 0.3240 & 0.3315 & 0.5033 & 0.2460 & 0.2535 & 0.4253 & 0.1680 & 0.1755 & 0.3473 \\
\hline $\mathrm{U}_{5}$ & 0.3315 & 0.3240 & 0.3315 & 0.2535 & 0.2460 & 0.2535 & 0.1755 & 0.1680 & 0.1755 \\
\hline $\mathrm{U}_{6}$ & 0.5033 & 0.3315 & 0.3240 & 0.4253 & 0.2535 & 0.2460 & 0.3473 & 0.1755 & 0.1680 \\
\hline $\mathrm{U}_{7}$ & 0.4020 & 0.4095 & 0.5813 & 0.3240 & 0.3315 & 0.5033 & 0.2460 & 0.2535 & 0.4253 \\
\hline $\mathrm{U}_{8}$ & 0.4095 & 0.4020 & 0.4095 & 0.3315 & 0.3240 & 0.3315 & 0.2535 & 0.2460 & 0.2535 \\
\hline $\mathrm{U}_{9}$ & 0.5813 & 0.4095 & 0.4020 & 0.5033 & 0.3315 & 0.3240 & 0.4253 & 0.2535 & 0.2460 \\
\hline
\end{tabular}

Note: Data is calculated based on the distance between the imported and exported container yard areas of the container terminal of Humen Port in Dongguan and the heavy load speed of the container truck. 


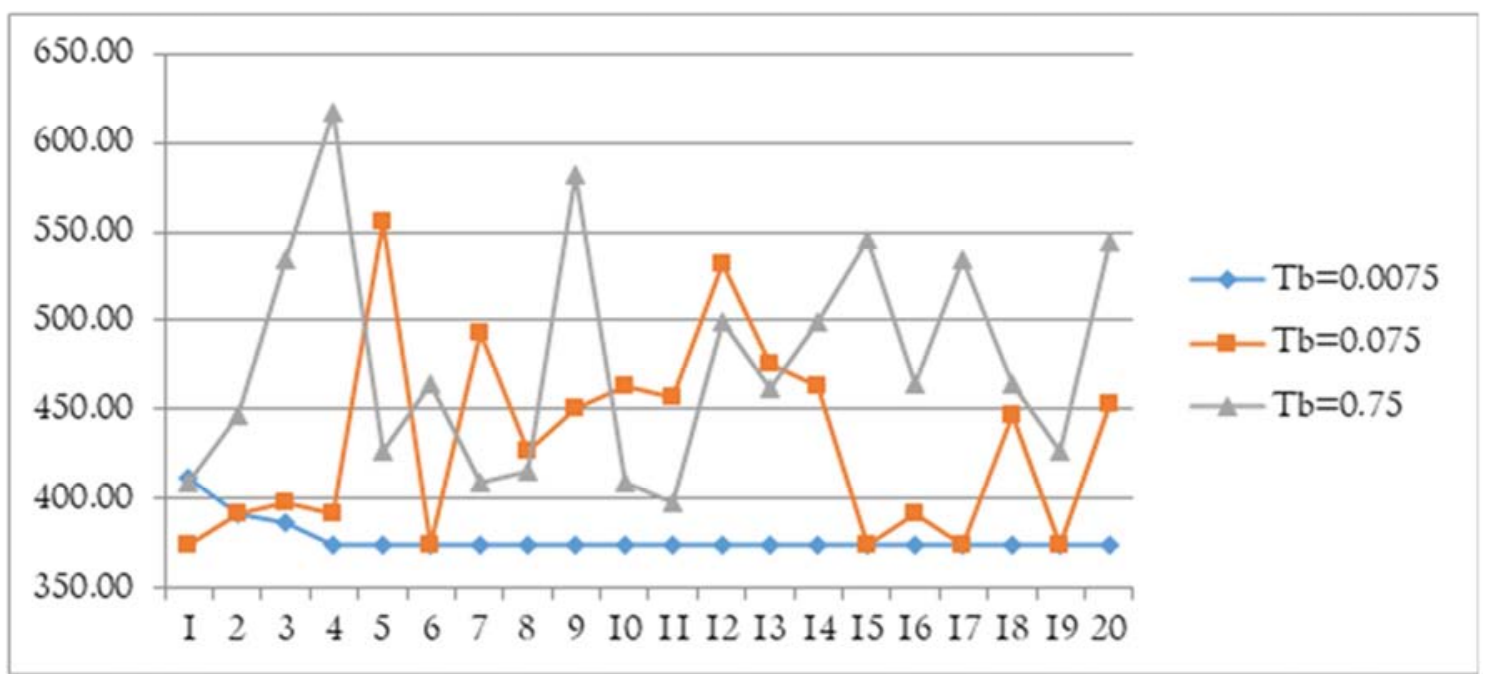

Note: $\mathrm{Tb}$ indicates the mutation rate.

Figure 6. Flow chart for solving collaborative scheduling mode of container trucks in container terminal.

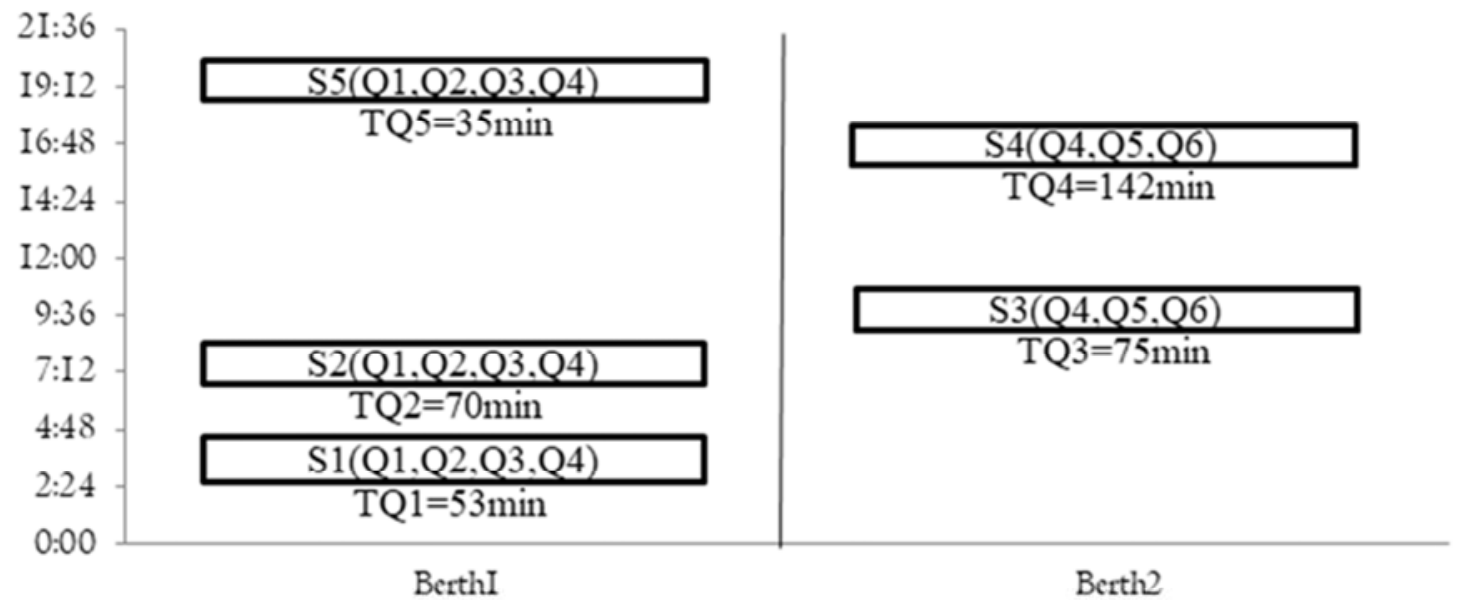

Note: TQ indicates the operation time of quay cranes, and the brackets indicate the quay cranes to which the ship is assigned.

Figure 7. Cooperative operation of ship berths and quay cranes.

Figure 7 shows the Gantt chart of the cooperation between the berths and the quay cranes obtained after the convergence of the objective function. This figure shows the order of the five arriving ships ( $\mathrm{S} 1$ to S5), the berths of the ships docked, the number of quay cranes configured, the serial numbers of the ships, and the operation times.

Figure 7 shows the Gantt chart of the cooperation between the berths and the quay cranes obtained after the convergence of the objective function. This figure shows the order of the five arriving ships (S1 to S5), the berths of the ships docked, the number of quay cranes configured, the serial numbers of the ships, and the operation times.

The docking position of the ship and the allocation of the quay cranes indicate that under the strategy of coordinated dispatching and unloading synchronization, the optimal driving path of the container truck corresponding to each ship and the transportation time required for the path are shown in Tables 9, 10, 11, 12, and 13 .
According to the objective function, the operation time of the quay cranes and the transportation time of the container trucks are solved. The overall operation time of all the operating ships of the container terminal within $24 \mathrm{~h}$ is $1546.67 \mathrm{~min}$, as shown in Table 14.

\subsubsection{Comparative Analysis}

Under the same data, the transportation time of a one-way task for container trucks to complete loading or unloading is shown in Table 15. Compared with the container operation of loading and unloading cooperative scheduling, the ship production operation in one-way operation takes a significantly longer time. Thus, the container truck cooperative scheduling mode of the container terminal is more advantageous. In the container terminal operating environment, the five ships saved approximately $23.43 \%$ (= $473.35 / 2020.03$ ) of the operation time under the loading and unloading coordinated container operation. 
Table 9. Container truck driving path and transportation time of the first ship (unit: minute).

\begin{tabular}{llll}
\hline Driving path & Number of loading containers & Number of unloading containers & Transportation time \\
\hline $\mathrm{S}_{1} \rightarrow \mathrm{U}_{1} \rightarrow \mathrm{L}_{4} \rightarrow \mathrm{S}_{1}$ & 50 & 50 & 28.92 \\
$\mathrm{~S}_{1} \rightarrow \mathrm{U}_{1} \rightarrow \mathrm{L}_{1} \rightarrow \mathrm{S}_{1}$ & 40 & 40 & 22.51 \\
$\mathrm{~L}_{1} \rightarrow \mathrm{S}_{1} \rightarrow \mathrm{L}_{1}$ & 20 & 0 & 2.16 \\
$\mathrm{~S}_{1} \rightarrow \mathrm{U}_{2} \rightarrow \mathrm{L}_{2} \rightarrow \mathrm{S}_{1}$ & 50 & 50 & 36.35 \\
$\mathrm{~S}_{1} \rightarrow \mathrm{U}_{3} \rightarrow \mathrm{L}_{2} \rightarrow \mathrm{S}_{1}$ & 30 & 30 & 27.14 \\
$\mathrm{~S}_{1} \rightarrow \mathrm{U}_{3} \rightarrow \mathrm{L}_{3} \rightarrow \mathrm{S}_{1}$ & 30 & 30 & 32.12 \\
Total & 220 & 200 & 149.21 \\
\hline
\end{tabular}

Table 10. Container truck driving path and transportation time of the second ship (unit: minute).

\begin{tabular}{llll}
\hline Driving path & Number of loading containers & Number of unloading containers & Transportation time \\
\hline $\mathrm{S}_{2} \rightarrow \mathrm{U}_{2} \rightarrow \mathrm{L}_{5} \rightarrow \mathrm{S}_{2}$ & 70 & 70 & 51.99 \\
$\mathrm{~S}_{2} \rightarrow \mathrm{U}_{3} \rightarrow \mathrm{L}_{3} \rightarrow \mathrm{S}_{2}$ & 80 & 80 & 45.02 \\
$\mathrm{~S}_{2} \rightarrow \mathrm{U}_{4} \rightarrow \mathrm{L}_{4} \rightarrow \mathrm{S}_{2}$ & 90 & 90 & 110.39 \\
$\mathrm{~S}_{2} \rightarrow \mathrm{U}_{4} \rightarrow \mathrm{S}_{2}$ & 0 & 10 & 11.48 \\
$\mathrm{~S}_{2} \rightarrow \mathrm{U}_{3} \rightarrow \mathrm{L}_{5} \rightarrow \mathrm{S}_{2}$ & 20 & 20 & 17.66 \\
$\mathrm{~S}_{2} \rightarrow \mathrm{U}_{5} \rightarrow \mathrm{S}_{2}$ & 0 & 30 & 25.17 \\
Total & 260 & 300 & 261.71 \\
\hline
\end{tabular}

Table 11. Container truck driving path and transportation time of the third ship (unit: minute).

\begin{tabular}{llll}
\hline Driving path & Number of loading containers & Number of unloading containers & Transportation time \\
\hline $\mathrm{S}_{3} \rightarrow \mathrm{U}_{5} \rightarrow \mathrm{L}_{5} \rightarrow \mathrm{S}_{3}$ & 40 & 40 & 35.32 \\
$\mathrm{~S}_{3} \rightarrow \mathrm{U}_{6} \rightarrow \mathrm{L}_{6} \rightarrow \mathrm{S}_{3}$ & 40 & 40 & 28.75 \\
$\mathrm{~L}_{6} \rightarrow \mathrm{S}_{3} \rightarrow \mathrm{L}_{6}$ & 10 & 0 & 7.05 \\
$\mathrm{~S}_{3} \rightarrow \mathrm{U}_{7} \rightarrow \mathrm{L}_{4} \rightarrow \mathrm{S}_{3}$ & 70 & 70 & 95.69 \\
$\mathrm{~L}_{2} \rightarrow \mathrm{S}_{3} \rightarrow \mathrm{L}_{2}$ & 60 & 0 & 33.90 \\
$\mathrm{~L}_{3} \rightarrow \mathrm{S}_{3} \rightarrow \mathrm{L}_{3}$ & 80 & 0 & 45.20 \\
Total & 300 & 150 & 245.91 \\
\hline
\end{tabular}

Table 12. Container truck driving path and transportation time of the fourth ship (unit: minute).

\begin{tabular}{llll}
\hline Driving path & Number of loading containers & Number of unloading containers & Transportation time \\
\hline $\mathrm{S}_{4} \rightarrow \mathrm{U}_{2} \rightarrow \mathrm{L}_{5} \rightarrow \mathrm{S}_{4}$ & 90 & 90 & 66.84 \\
$\mathrm{~S}_{4} \rightarrow \mathrm{U}_{5} \rightarrow \mathrm{L}_{8} \rightarrow \mathrm{S}_{4}$ & 30 & 30 & 22.16 \\
$\mathrm{~S}_{4} \rightarrow \mathrm{U}_{3} \rightarrow \mathrm{L}_{6} \rightarrow \mathrm{S}_{4}$ & 50 & 50 & 28.92 \\
$\mathrm{~S}_{4} \rightarrow \mathrm{U}_{3} \rightarrow \mathrm{L}_{9} \rightarrow \mathrm{S}_{4}$ & 20 & 20 & 11.88 \\
$\mathrm{~S}_{4} \rightarrow \mathrm{U}_{6} \rightarrow \mathrm{L}_{9} \rightarrow \mathrm{S}_{4}$ & 60 & 60 & 44.06 \\
$\mathrm{~S}_{4} \rightarrow \mathrm{U}_{4} \rightarrow \mathrm{L}_{7} \rightarrow \mathrm{S}_{4}$ & 90 & 90 & 111.79 \\
$\mathrm{~S}_{4} \rightarrow \mathrm{U}_{4} \rightarrow \mathrm{L}_{5} \rightarrow \mathrm{S}_{4}$ & 10 & 10 & 10.61 \\
$\mathrm{~S}_{4} \rightarrow \mathrm{U}_{6} \rightarrow \mathrm{L}_{8} \rightarrow \mathrm{S}_{4}$ & 50 & 50 & 42.88 \\
$\mathrm{~S}_{4} \rightarrow \mathrm{U}_{6} \rightarrow \mathrm{S}_{4}$ & 50 & 0 & 26.83 \\
Total & 450 & 400 & 365.97 \\
\hline
\end{tabular}

Table 13. Container truck driving path and transportation time of the fifth ship (unit: minute).

\begin{tabular}{llll}
\hline Driving path & Number of loading containers & Number of unloading containers & Transportation time \\
\hline $\mathrm{S}_{5} \rightarrow \mathrm{U}_{6} \rightarrow \mathrm{L}_{9} \rightarrow \mathrm{S}_{5}$ & 30 & 30 & 37.26 \\
$\mathrm{~L}_{9} \rightarrow \mathrm{S}_{5} \rightarrow \mathrm{L}_{9}$ & 30 & 0 & 25.37 \\
$\mathrm{~S}_{5} \rightarrow \mathrm{U}_{8} \rightarrow \mathrm{L}_{8} \rightarrow \mathrm{S}_{5}$ & 20 & 20 & 20.78 \\
$\mathrm{~L}_{8} \rightarrow \mathrm{S}_{5} \rightarrow \mathrm{L}_{8}$ & 30 & 0 & 16.10 \\
$\mathrm{~S}_{5} \rightarrow \mathrm{U}_{7} \rightarrow \mathrm{L}_{7} \rightarrow \mathrm{S}_{5}$ & 50 & 50 & 41.58 \\
$\mathrm{~L}_{7} \rightarrow \mathrm{S}_{5} \rightarrow \mathrm{L}_{7}$ & 20 & 0 & 7.78 \\
Total & 180 & 100 & 148.87 \\
\hline
\end{tabular}

Table 14. Overall operation time of all inbound ships (unit: minute).

\begin{tabular}{llll}
\hline Inbound ship & Operation time of the quay cranes & Transportation time of container truck & Total \\
\hline $\mathrm{S}_{1}$ & 53 & 149.21 & 202.21 \\
$\mathrm{~S}_{2}$ & 70 & 261.71 & 331.71 \\
$\mathrm{~S}_{3}$ & 75 & 245.91 & 320.91 \\
$\mathrm{~S}_{4}$ & 142 & 365.97 & 507.97 \\
$\mathrm{~S}_{5}$ & 35 & 148.87 & 183.87 \\
Total & 375 & 1171.67 & 1546.67 \\
\hline
\end{tabular}


Table 15. Time-consuming comparison between cooperative scheduling operations and one-way loading and unloading operations (unit: minute).

\begin{tabular}{llll}
\hline Inbound ship & Cooperative operation time (A) & One-way operation time (B) & Difference (B-A) \\
\hline $\mathrm{S}_{1}$ & 202.21 & 254.29 & 52.08 \\
$\mathrm{~S}_{2}$ & 331.71 & 413.81 & 82.10 \\
$\mathrm{~S}_{3}$ & 320.91 & 428.04 & 107.13 \\
$\mathrm{~S}_{4}$ & 507.97 & 688.48 & 180.51 \\
$\mathrm{~S}_{5}$ & 183.87 & 235.41 & 51.53 \\
Total & 1546.67 & 2020.03 & 473.35 \\
\hline
\end{tabular}

\section{Conclusion}

This paper analyzes and studies all aspects of the transportation and production operations of container terminals. In this paper, the container terminal truck scheduling problem based on a collaborative scheduling strategy is modeled and solved to optimize the terminal production efficiency. Then, the Humen Port Container Terminal in Dongguan is taken as an example to solve the analysis of the berth position of the inbound ship of the container terminal and the allocation information of the corresponding quay cranes of ship and then obtain the transportation operation path and time of the container truck at the front and the yard of the terminal for all ships to have the shortest operation time. According to the analysis results, approximately $23.43 \%$ of the operation time can be saved under the loading and unloading coordinated container operation. The model constructed in this study mainly considers the production and operation time of the ship at the dock and ignores other performance indicators of the terminal production operation, such as the production cost of the terminal and the green carbon emissions of the terminal. Therefore, these performance indicators can be considered in future research for the design of the model to be more consistent with the actual situation of terminals and suitable for the optimization of terminal scheduling.

\section{References}

[1] China Port and Harbors Association. (2017) Statistical data. Available at: http://www.port.org.cn/list/1006_1077_1.htm.

[2] CNR News. (2017) Guangzhou 2017 major project big secret. Available http://www.cnr.cn/gd/gdkx/20170613/t20170613_523799097. shtml.

[3] Zhu, R. Y. (2014) Collaborative Optimization of Shipping Logistics Service Supply Chain. PhD diss., Wuhan University of Technology.

[4] Zhang, F. F. (2017) Optimization Research for Yard Truck Scheduling in Container Terminal. Master diss., Shenzhen University.

[5] Xing, Z. C. (2017) Truck Scheduling Optimization of Container Terminals Based on Real-Time Information. Master diss., Zhejiang University.

[6] Yan, Z., and Tao, D. X. (2006) Technology of Truck Process
System of Container Terminals Based on Dynamic Optimized Combination. Journal of Wuhan University of Technology (Information \& Management Engineering) 28 (04): 26-29.

[7] Han, X. L. (2005) Resources Allocation in Container Terminal Charge/Discharge Operation. PhD diss., Shanghai Maritime University.

[8] Zeng, Q. C., and Yang, Z. Z. (2008) A scheduling model and Q-learning algorithm for yard trailers at container terminals. Journal of Harbin Engineering University 29 (01): 1-4.

[9] Ji, M. J., Liu, F. S. Li, G. J., and Jin, Z. H. (2010) Truck Routing and Allocation Optimization Based on Loading and Unloading Simultaneous Operations in a Container Terminal. Journal of Dalian Maritime University 36 (01): 47-50.

[10] Zeng, Q. C., and Yang, Z. Z. (2007) Two-phase Tabu Search Algorithm of Unloading Operation Scheduling Project in Container Wharf. Journal of Traffic and Transportation Engineering 7 (02): 109-112+122.

[11] Xu, C. J., and Tao, D. X. (2007) A Study of Container Truck Dynamic Dispatch Method Based on Multi-Objective Fuzzy Decision. Journal of Wuhan University of Technology (Information \& Management Engineering) 29 (04): 56-59.

[12] Wang, Y., Sun, L. Y., and Li, G. (2008) A Variable Neighborhood Tabu Search for Container Vehicle Routing Problem. Industrial Engineering and Management 13 (05): 6-10+28.

[13] Liang, C. J., and Shen, J. J. (2016) Study on Problem of Quay Cranes and Container Trucks Scheduling with Consideration of Handling Order. Application Research of Computers 33 (12): 3591-3595.

[14] Shao, Q. Q. (2017) Allocation and Scheduling Optimization of Yard crane in Container Yard Based on Truck Appointment Mechanism. PhD diss., Dalian Maritime University.

[15] Feng, C. H. (2011) Study on the Optimization of Scheduling for Berth-Crane-Trailer at Container Terminal. Master diss., Dalian Maritime University.

[16] Tao, J. H., Wang, Y. X., and Xu, B. (2016) Container Terminal Intelligent Management Optimization Strategy. Beijing: China Fortune Press.

[17] Liu, M., Tang, X., and Dai, M. H. (2015) Container Terminal Operation Practice. Beijing: China Communications Press.

[18] Liu, L. Y. (2011) Humen Port Container Business Development Strategy. Containerization 22 (05): 4-5.

[19] Huozhanggui. (2017) 2017 Domestic Port Container Terminal Single Evaluation Ranking publicity. Available at: https://www.huozhanggui.net/xinwen/hangye/5981.html.

[20] PSA DGCT. (2018) PSA Dongguan Container Terminal. Available at: http://www.psa-dgct.com/aboutus.html. 